\title{
Capillary desaturation curve: does low salinity surfactant flooding significantly reduce the residual oil saturation?
}

\author{
Davood Zivar $^{1} \cdot$ Peyman Pourafshary ${ }^{1}$ (D) Nikoo Moradpour $^{1}$
}

Received: 8 October 2020 / Accepted: 17 December 2020 / Published online: 2 January 2021

(c) The Author(s) 2021

\begin{abstract}
Different oil displacement experiments conducted on sandstone and carbonate samples show that low salinity water (LSW) injection can reduce the residual oil saturation (ROS). Recently, surfactant flooding (SF) in combination with low salinity water (known as low salinity surfactant (LSS) flooding) is proposed as a potentially promising hybrid enhanced oil recovery (EOR) process. A lower ROS is reported for a LSS process compared to that seen in SF or with LSW at the same capillary number. The capillary desaturation curve (CDC) is a well-known tool to study the effect of viscous and capillary forces on ROS for different EOR techniques. In this study, ROS data of various LSW, SF, and LSS flooding experiments at different capillary numbers are collected to develop a CDC to analyze the performance of the hybrid LSS method. This can help to analyze the effect of the hybrid method on an extra improvement in sweep efficiency and reduction in residual oil. A lower ROS is observed for LSS compared to LSW and SF in the same capillary number range. Our study shows different behaviors of the hybrid method at different ranges of capillary numbers. Three regions are identified based on the capillary number values. The difference in ROS is not significant in the first region (capillary number in the range of $10^{-7}-10^{-5}$ ), which is not applicable in the presence of surfactant due to the low interfacial tension value. A significant reduction in ROS is observed in the second region (capillary number in the range of $10^{-5}-10^{-2}$ ) for LSS compared to SF. This region is the most practical range for SF and LSS flooding. Hence, the application of LSS provides a noticeable benefit compared to normal EOR techniques. In the third region (capillary numbers greater than $10^{-2}$ ), where the surfactant flooding is a better performer, the difference in ROS is negligible.
\end{abstract}

Keywords Capillary desaturation curve $\cdot$ Low salinity water flooding $\cdot$ Surfactant flooding $\cdot$ Residual oil saturation · Capillary number $\cdot$ Low salinity surfactant flooding

$\begin{array}{ll}\text { Abbreviations } \\ \text { CDC } & \text { Capillary desaturation curve } \\ \text { EOR } & \text { Enhanced oil recovery } \\ \text { IFT } & \text { Interfacial tension } \\ \text { LSS } & \text { Low salinity surfactant } \\ \text { LSW } & \text { Low salinity water } \\ \text { OOIP } & \text { Original oil in place } \\ \text { ROS } & \text { Residual oil saturation } \\ \text { SF } & \text { Surfactant flooding } \\ N c & \text { Capillary number (dimensionless) } \\ V & \text { Darcy velocity (m/s) } \\ \mu & \text { Dynamic viscosity (Pa.s) } \\ & \end{array}$

Peyman Pourafshary

peyman.pourafshary@nu.edu.kz

1 Department of Petroleum Engineering, School of Mining and Geosciences, Nazarbayev University, Nur-Sultan, Kazakhstan

$\begin{array}{ll}\sigma & \text { Interfacial tension between oil and water }(\mathrm{N} / \mathrm{m}) \\ \theta & \text { Contact angle (degree }\end{array}$

\section{Introduction}

It is perceived that primary and secondary recovery mechanisms of oil recovery are incapable of fully draining the reservoir on account of domineering capillary forces or the deficient sweep efficiency of the injection fluid. This highlights the need for more effective and advanced approaches to move the remaining oil and increase drainage efficiency. As the most commonly employed secondary method of improved oil recovery (IOR), water flooding maintains the reservoir pressure and mobilizes the trapped oil.

In 1959, Martin examined the influence of injection brine composition, and the results displayed higher oil recovery because of salinity reduction, due to the migration of

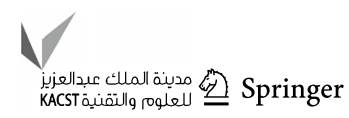


clay particles (Martin (1959)). The topic remained underresearched until 1967 when it was revived by Bernard's study, deploying laboratory investigations on Berea sandstone cores. The results highlighted the influence of salinity reduction on improving oil recovery (Bernard 1967). Consequently, a new line of research on active mechanisms during low salinity water (LSW) has flourished, considering fine migration (Fouladi et al. 2019; Tang and Morrow 1999), pH variation (Austad et al. 2010; McGuire et al. 2005; Morrow and Buckley 2011), multicomponent ion exchange (AlAbri et al. 2019; Lager et al. 2008; Moradpour et al. 2020; Shabani and Zivar 2020), double-layer expansion (Mahani et al. 2015; Lee, et al. 2011), and water micro-dispersion (Darvish Sarvestani et al. 2019; Mahzari and Sohrabi 2015) as the most efficient mechanisms. These studies have been extensively performed at various scales such as molecular scale (Khosravi et al. 2020), pore level scale (Akai et al. 2020; Mirchi 2018), laboratory (Lager et al. 2008; Darvish Sarvestani et al. 2019), and field (Vledder et al. 2010) scales.

In spite of the beneficial impact of IOR methods regarding enhancing oil recovery, significant amount of original oil in place (OOIP) still remains unrecovered due to the low oil mobility and reservoir heterogeneity. Therefore, several enhanced oil recovery (EOR) techniques are applied to increase the microscopic/macroscopic oil sweep efficiency (Santoso et al. 2020). Chemical EOR techniques are among the most conventional ones as they are viable and cost-effective to be implemented in the fields (Druetta and Picchioni 2020). The chemicals are injected in various scenarios along with water and affect the interactions in CBR (carbohydrate, brine, rock) system favorably to increase the oil mobility and the displacement. Polymer, surfactant, alkali, foam, and nanofluids injections and different combinations of them are known as chemical EOR methods which improve oil recovery by lowering interfacial tension between oil and water, increasing the viscosity of the injected water, and modifying the rock wettability toward more water-wet status (Nwidee et al. 2016; Gbadamosi et al. 2019). Surfactants are amphiphilic (hydrophilic and hydrophobic simultaneously) agents that reduce the oil-water interfacial tension (IFT) and form water-in-oil or oil-in-water emulsions (Sheng 2015; Torrealba and Hoteit 2019). As a result, the trapped unrecovered oil is redistributed and mobilized leading to the incremental oil recovery of up to 30\% OOIP (Massarweh and Abushaikha 2020). Surfactant injection is a widely used EOR method since there is a wide range of surfactant types each of which is suitable to use under desired criteria of water salinity, reservoir temperature, adsorption to reservoir rock, and operational costs.

Surfactant flooding (SF), as a chemical EOR method, is utilized to obtain higher levels of oil extraction by reducing the IFT and adjusting wettability, which leads to the movement of capillary trapped oil. The application of surfactants in EOR goes back to the 1920s, where laboratory investigations by Uren and Fahmy (1927) signaled increased oil recovery efficiency due to the injection of different solutions of water-soluble agents. A reduction in IFT was introduced as the main reason for the observed EOR (Uren and Fahmy 1927). After introducing the surfactant as an effective agent, further studies on multiphase flow phenomena during SF led to the recognition of the corresponding parameters, resulting in the optimization of the ultimate oil recovery factor (Glover et al. 1979; Healy et al. 1976; Hirasaki et al. 1983; Nelson and Pope 1978). In between, Fathi and Ramirez (1984) tried to determine the best injection strategy for a tertiary SF to maximize the amount of oil produced and minimize the surfactant cost by using the distributed parameter control theory. The results showed that the mentioned theory was able to optimize the SF operation for two different trends of IFT variation in the core scale (Fathi and Ramirez 1984). Schilling et al. (1995) studied the drainageimbibition mechanisms that lead to mobilization of residual oil saturation (ROS) during tertiary SF in two homogeneous and heterogeneous glass micromodels. In the reported results, the values of ROS after SF were similar, but microscopic sweep and recovery efficiency were higher for the homogeneous model compared to the heterogeneous model. This was due to the fact that surfactant in the heterogeneous model finds the path with lower resistance resulting in early breakthrough and lower sweep efficiency (Schilling et al. 1995).

Abeysinghe et al. (2012a) studied oil recovery mechanisms using unsteady state and steady state SF on mixedwet Brea core samples. A low ROS was observed due to the presence of the surfactant and its IFT reduction ability. The capillary desaturation curve (CDC) was used to interpret the results, where a slow decline in ROS was observed with capillary number increment. In addition, no plateau of ROS and no critical value for capillary number were reported by the researchers (Abeysinghe et al. 2012a). In another study by Abeysinghe et al. (2012b), 4 core samples were flooded by formation water followed by SF to study the ROS for two water- and mixed-wet states of wettability. The results showed a higher recovery factor during the SF flooding in the case of the mixed-wet wettability compared to the waterwet. It was also shown that the reduction of ROS in mixedwet core samples depends on the values of the injected pore volumes (Abeysinghe et al. 2012b).

The efficiency of the surfactant can be influenced by the active ions in brine and its salinity. Decreasing the IFT using a surfactant agent is dependent upon various factors, including brine concentration. Accordingly, a mixture of surfactant and low salinity water flooding was deployed as a new hybrid method for EOR known as low salinity surfactant (LSS) flooding (Pourafshary and Moradpour 2019). The main idea of a LSS process is to alter the wettability of the 
porous media and simultaneously reduce the IFT between the water and oil phases. The LSS process could be costeffective and commercially available compared to other EOR methods, because at lower salinity, the adsorption and consequently retention of surfactant is less, which helps to reduce the costs of the operation (Glover et al. 1979). In addition, when the salinity of the environment is low, more surfactant systems are commercially available. Alagic and Skauge (2010) first introduced the LSS process, where 3 LSW/SW flooding experiments followed by LSS were conducted on Brea sandstone cores. The obtained results showed significant enhancement in the ultimate oil recovery, up to 33\% of original oil in place (OOIP) (Alagic and Skauge 2010). After that, further investigations in the core scale were employed by researchers to study the effect of the initial wettability state of the core samples (Alagic et al. 2011), evaluate the performance of the optimum salinity during LSS (Johannessen and Spildo 2013; Khanamiri et al. 2015), study the effect of concentration of cations $\left(\mathrm{Na}^{+}, \mathrm{Ca}^{2+}\right.$, and $\left.\mathrm{Mg}^{2+}\right)$ and salinity in the composition of brine (Hosseinzade Khanamiri et al. 2016a,2016b) and to assess the effect of removing alkali associated with surfactant on either high salinity and LSS flooding (Zhang et al. 2015). In addition, in a study in the microscopic scale by Mirchi (2018), it is visually demonstrated that LSS shows higher performance compared to LSW or high salinity water flooding in carbonate core samples. In the mentioned study, fluid distribution and in situ contact angle distribution in the porous media were shown for the oil-wet system (Mirchi 2018).

The main target of different methods of EOR, such as LSW, SF, and LSS, is to reduce the ROS, and this can be done by increasing the capillary number in the system. The competition between capillary and viscous forces, which are the controlling forces in a two-phase flow at the pore level, is known as the capillary number (Eq. 1). The magnitude of viscous forces is affected by permeability, applied pressure, and viscosity. The affecting parameters on the capillary force are IFT, state of wettability, pore size distribution (PSD), and geometry of the pores.

$N_{c}=\frac{V \mu}{\sigma}$

where $N_{c}$ stands for the capillary number, $\mu$ is the dynamic viscosity of the displacing fluid, $V$ is the Darcy velocity, and $\sigma$ is the interfacial tension between oil and water.

It has been shown that the capillary number and ROS are related such that a greater capillary number leads to a lower ROS. Considering Eq. 1, increasing the capillary number can be carried out in 3 theoretical ways, which are: (1) increasing the displacement velocity, (2) increasing the viscosity of the displacing fluid, or (3) decreasing the IFT. Practically, it may not be possible to increase the velocity or viscosity by such a value, regarding the required or created injector-producer significant pressure difference. Such an excessive pressure difference may result in severe formation damage. To conclude, the most practical technique of increasing the capillary number is the reduction of the IFT.

The CDC is a plot of ROS versus the capillary number, where it is one of the most important input parameters in reservoir simulation software for EOR (Oughanem et al. 2013) and is influenced by the wettability and the PSD of the porous medium. Figure 1 presents a schematic of the $\mathrm{CDC}$, where the logarithmic $\mathrm{x}$-axis is representative of the capillary number, and the normal $y$-axis shows the residual saturation of the non-wetting phase. In this figure, there is a normal range of capillary numbers for water flooding, where the ROS is usually high in this range. After passing the critical capillary number using an EOR method,
Fig. 1 Schematic of the capillary desaturation curve (Lake 1989 adapted from Lake (1989))
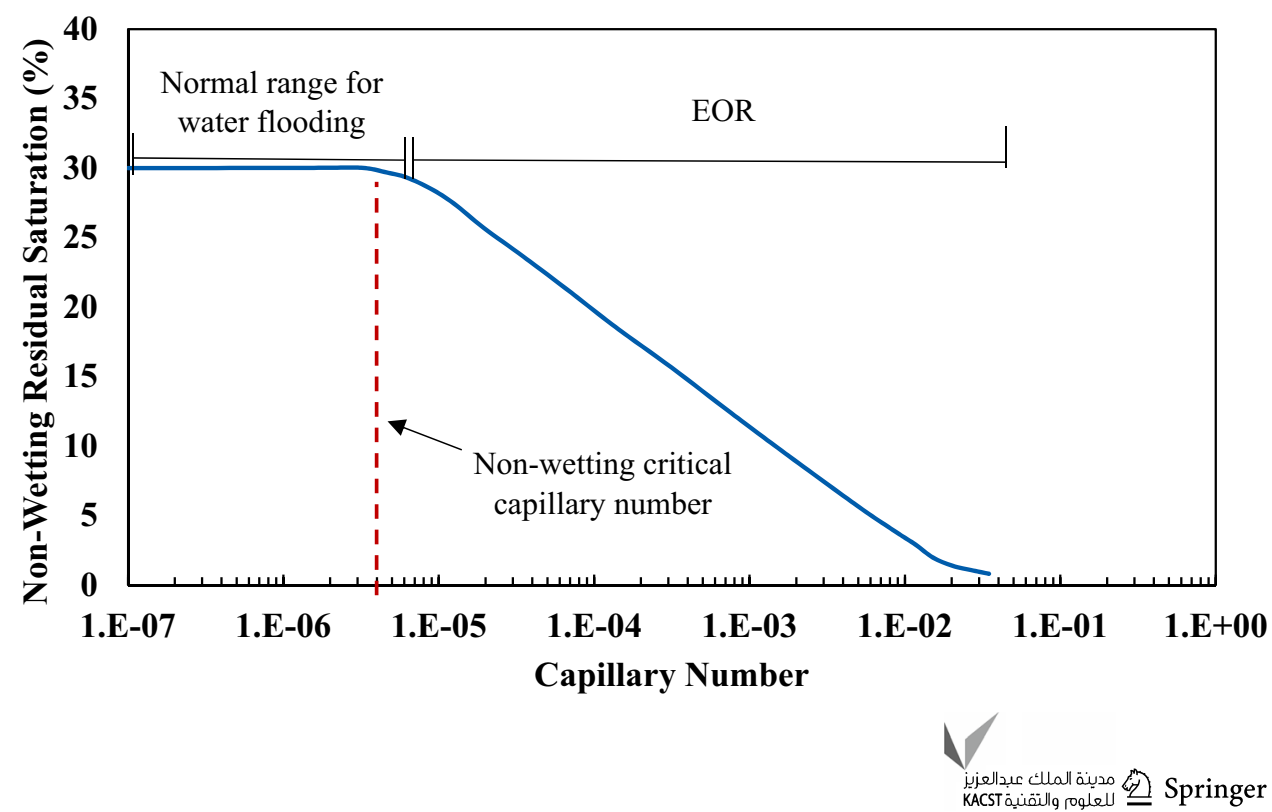
a reducing trend can be observed for ROS. Garnes et al. (1990) reported $4 \times 10^{-6}$ as the critical capillary number of water-wet Berea sandstones (Garnes et al. 1990). Since the capillary number has a significant impact on the amount of trapped fluid, the ROS is commonly measured experimentally as a function of the capillary number to obtain the CDC (Sahimi 1993). On the other hand, a large change in the capillary number is required to significantly change the ROS due to the logarithmic $\mathrm{x}$-axis of CDC.

LSW is able to reduce the ROS by altering the wettability of the rock, which is known to be the most effective mechanism in this method. It can also redistribute the remaining oil inside the pores because of rock/oil/brine interactions, but it cannot bring all the redistributed oil saturation into production due to the high governing capillary force. This is due to the fact that to bring the trapped redistributed oil inside the pores into production, we need to overcome the capillary force by reducing the IFT. SF, on the other hand, is able to reduce the IFT but does not work efficiently as a wettability modifier. Therefore, taking advantage of both LSW and SF could help to significantly reduce the ROS. The objective of this study is to investigate the ROS at different capillary numbers by using the CDC, which is a useful tool to investigate the performance of each mode of EOR, for various LSW, SF, and LSS flooding experiments.

\section{Datasets}

The idea of taking advantage of both the LSW and SF methods and establishing a hybrid method, known as LSS, has made researchers eager to study the performance of the LSS method through laboratory and modeling studies. Although the LSS method shows promising performance in core flooding experiments, only a few studies have been done on this method in the laboratory. In this section, we have tried to summarize the LSS experiments conducted by researchers in order to establish a dataset. The dataset consists of ROS and capillary number data. The ROS is calculated based on the reported ultimate recovery and OOIP of the core samples for each method. Figure 2 shows an example of the oil recovery and its corresponding ROS for an LSW flooding followed by LSS (Alagic and Skauge 2010). The capillary number is also calculated using the rock properties, fluid properties, and operational conditions, such as viscosity, porosity, injection rate, and IFT between brine solution and oil through Eq. 1. It should be mentioned that different definitions of the capillary number are presented in the literature. Each of them includes a specific parameter to capture the related phenomenon. For example, $\cos \theta$ uses in the denominator of the Eq. 1 to include the effect of wettability. However, using such a definition may cause a mathematical error because of the contact angles with values equal or close to 90 degrees, which is the normal contact angle range in the mixed-wet media (Mirchi 2018; Lin et al. 2019). Therefore, this study uses the capillary number formula in the format of Eq. 1, while all of the literature listed in Table 1 and Table 2 used the same definition.

In addition, the ROS and capillary number data of the LSW and SF methods are calculated/collected to compare with the LSS method.

It is worth noting that all the used data for LSW and LSS methods were achieved by core flooding experiments of synthetic/native core samples in the laboratory. The rock mineralogy of the used core samples is sandstone. The porosity and permeability of the core samples are in the range of
Fig. 2 Oil recovery and corresponding ROS for a LSW flooding followed by LSS (Alagic and Skauge 2010)

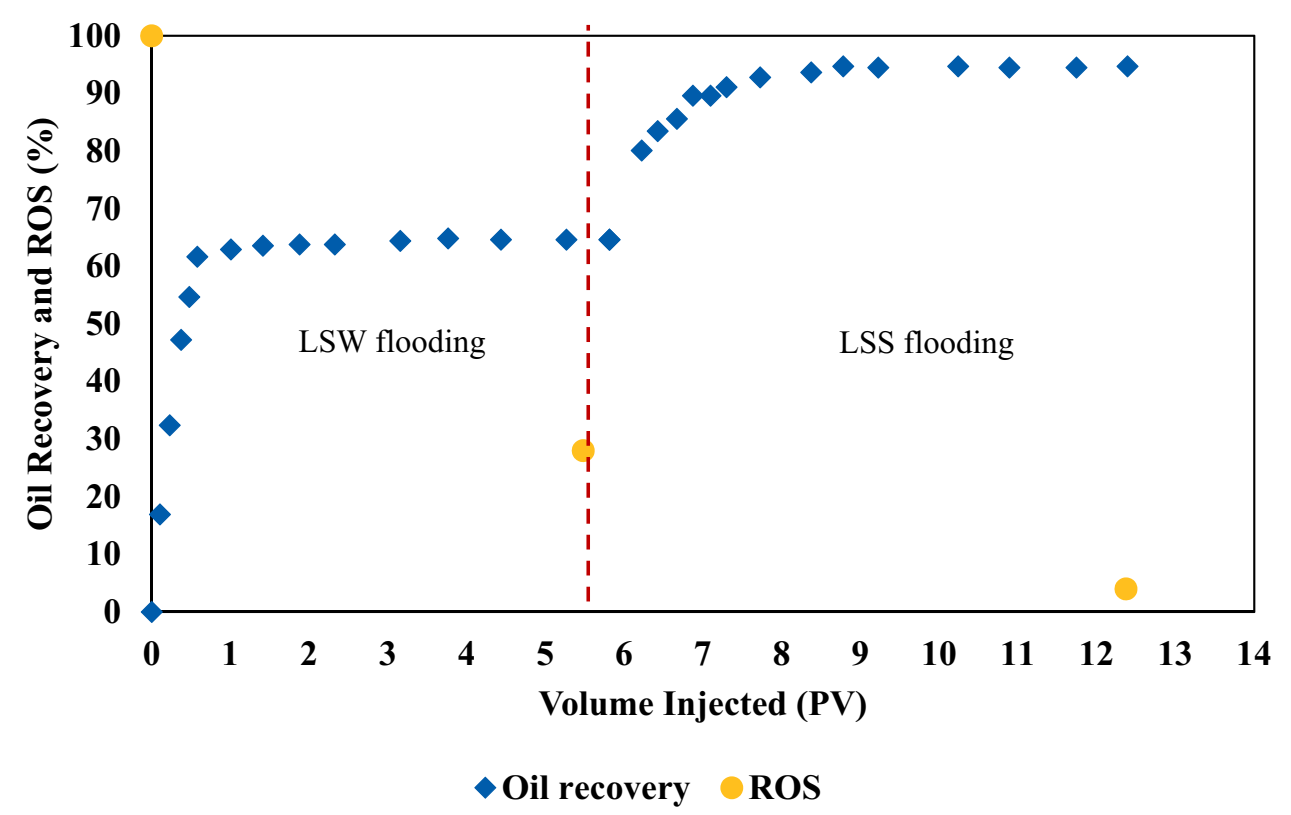




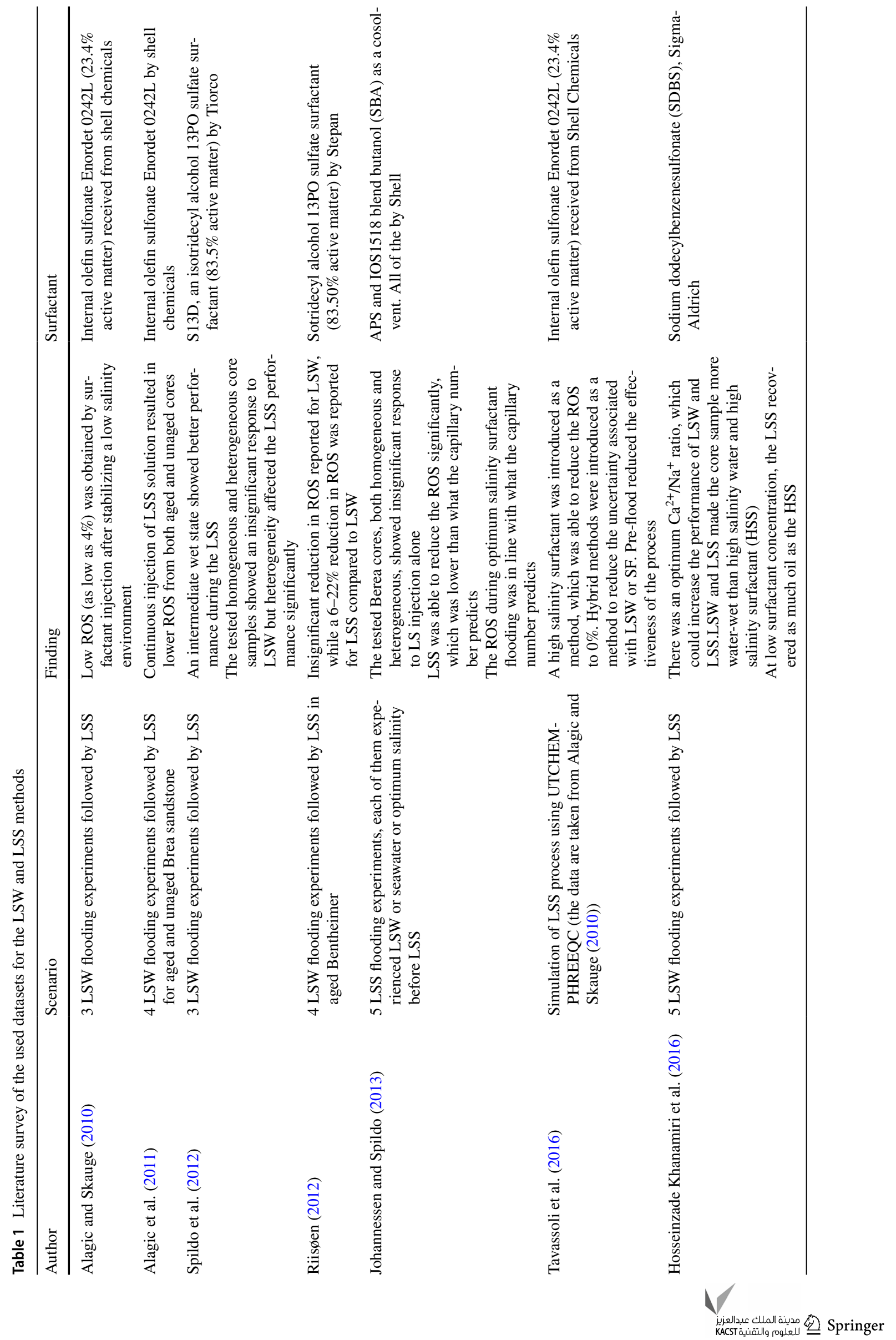


15.3-24.4\% and $85-2040 \mathrm{mD}$, respectively. Table 1 presents a literature survey of the data used for LSW and LSS methods. It is worth noting that flooding of the LSS was conducted after injection of the LSW for all experiments (tertiary recovery).

Table 2 presents a literature survey of the data used for the SF method. It should be mentioned that both laboratory and modeling studies were nominated for the data collection. The rock mineralogy of the used core samples is sandstone. The porosity and permeability of the samples are in the range of $22-25 \%$ and $418-657 \mathrm{mD}$, respectively.

\section{Results and discussion}

As mentioned, the ROSs and capillary numbers are calculated using the published data in the studies presented in Table 1 and Table 2, in order to create a dataset. The calculated ROSs and capillary numbers for the LSW, SF, and LSS methods are plotted in the form of the CDC in Fig. 3. This figure discusses the values of ROS at different capillary numbers for the mentioned methods. To do so, the CDC is divided into three regions, and each region is discussed in detail.

The first region stands for the capillary numbers in the range of less than $10^{-5}$. In this region, the capillary number is low, and consequently, ROS is high (usually more than $30 \%$ ). This region can stand for the normal range of water flooding but covers higher capillary numbers compared to the reported critical capillary number $\left(4 \times 10^{-6}\right)$ by Garnes et al. (1990) (Garnes et al. 1990). As presented in Fig. 3, all the LSW data are placed in this region and more specifically in the range of $10^{-7}$ and $10^{-6}$. All the data used in this study come from core flooding experiments, where the affecting parameters on the viscous force (viscosity and Darcy velocity) are in the same range. In addition, the range of the IFT between different types of brine and oil is not wide. It is worth mentioning that the use of different ions alters the brine-oil IFT values by only a few units, which is reported and confirmed in the literature (Bartels et al. 2019). Thus, the density of the LSW data in this region is high.

The use of the CDC for interpretation of the LSW data is a controversial question, which is still under investigation. It is mentioned in the literature that CDC is not an appropriate tool for the LSW method because of two reasons. The first reason is low changes in capillary number parameters when HSW changes to LSW, as mentioned above. The second reason is that the injection of LSW results in a more waterwet condition and higher ROS, which is in contradicts with observations (Bartels et al. 2019; Jadhunandan and Morrow 1995; Christensen and Tanino 2018). Although this question has not been answered yet, we believe CDC is applicable in our study because this research compares conducted and 
Fig. 3 Capillary desaturation curve for LSW, SF, and LSS methods

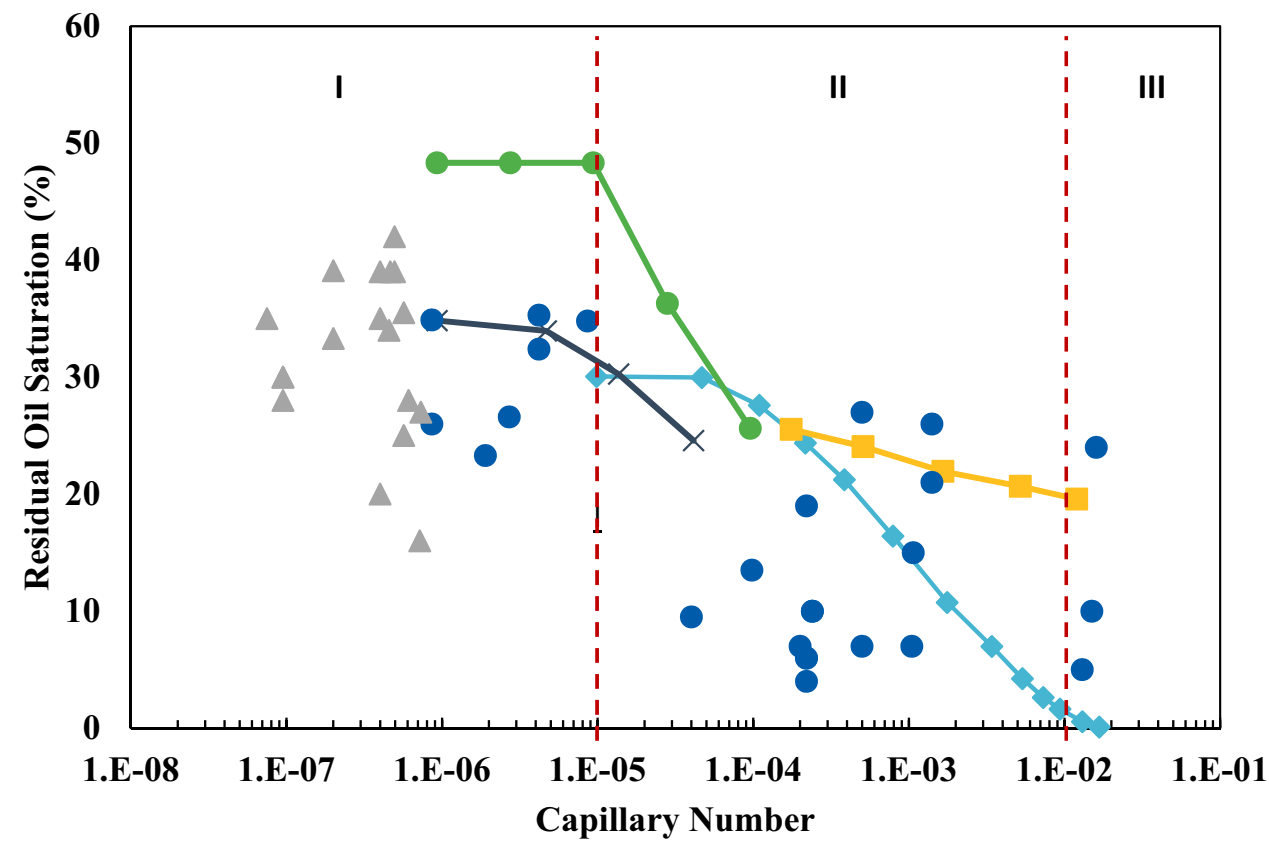

- LSS $\triangle$ LSW

$\neg-$ SF (Fathi and Ramirez (1984)) - -SF (Abeysinghe et al. (2012a))

$\star$ SF (Abeysinghe et al. (2012b)) - -SF (Abeysinghe et al. (2012b)) stabilized LSW experiments with LSS and SF. Therefore, the CDC does not have to explain the active mechanisms during the injection of a LSW.

In region I, the ROS of the LSW data is in the range $16-42 \%$ of OOIP, with an average of $32 \%$, which shows that a considerable amount of oil is left in the porous media. It is believed that large pores are contributing to the production and this amount of oil is trapped in the smaller pores and/ or in the corners of the porous media (Mirchi 2018). This is due to the fact that although the reduction of the salinity (or engineering the ions) of the water during LSW flooding can change the wettability of the porous media, it cannot significantly reduce the oil-brine IFT. Therefore, the LSW cannot invade into the small pores and/or remove the trapped oil in the corners, resulting in capillary trapping. Adding a surfactant into the injected LSW highlights the benefit of lowering the IFT. In order to discuss in more detail, one experiment from each of the nominated studies has been chosen to compare the LSW data and the corresponding LSS data, as presented in Fig. 4.

The presented CDC in Fig. 4 shows that the cooperation of surfactant with LSW can increase the capillary number and subsequently significant reduction in ROS. The capillary number changes show up to 3 orders of magnitude increment, while the magnitude of ROS is decreased by up to $30 \%$. The high increment of capillary number leads to the production of a higher volume of OOIP. For instance, Fig. 2 shows the oil recovery of the core sample B2 of the Alagic and Skauge (2010) study, and the corresponding ROS and capillary numbers for the two steps of LSW and LSS flooding are presented in Fig. 4. The injection of the LSS solution after flooding with LSW caused a significant increase in the recovery factor. It is believed that the significant reduction in ROS (higher oil recovery) observed could be due to two main reasons. The first reason is that surfactant is able to reduce the IFT, which causes invasion of the brine solution into smaller pores, results in bringing trapped oil into production. The second reason is that the redistributed oil and/ or destabilized oil layers by LSW injection because of rock/ oil/brine interactions and it is swept by the LSS as a result of capillary force reduction.

Some data of the SF are observed in this region because of the role of surfactant in the IFT reduction process, which leads to the higher capillary numbers. In addition, the reduction of ROS for SF data in this region is insignificant because the increment of the capillary number is insufficient and/or ineffective to mobilize the trapped oil in the pores. The data related to the LSS method are also limited to a few data, and show less magnitude of ROS.

The second region stands for the capillary numbers in the range of $10^{-5}$ and $10^{-2}$. In this region, the LSW data are absent, but the majority of the LSS data are scattered. Generally, the LSS data show lower ROS compared to the LSW data (appeared in the first region of CDC) due to the

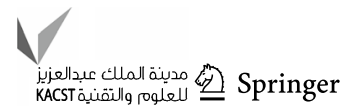


Fig. 4 Capillary desaturation curve for nominated LSW experiments and their corresponding LSS experiments

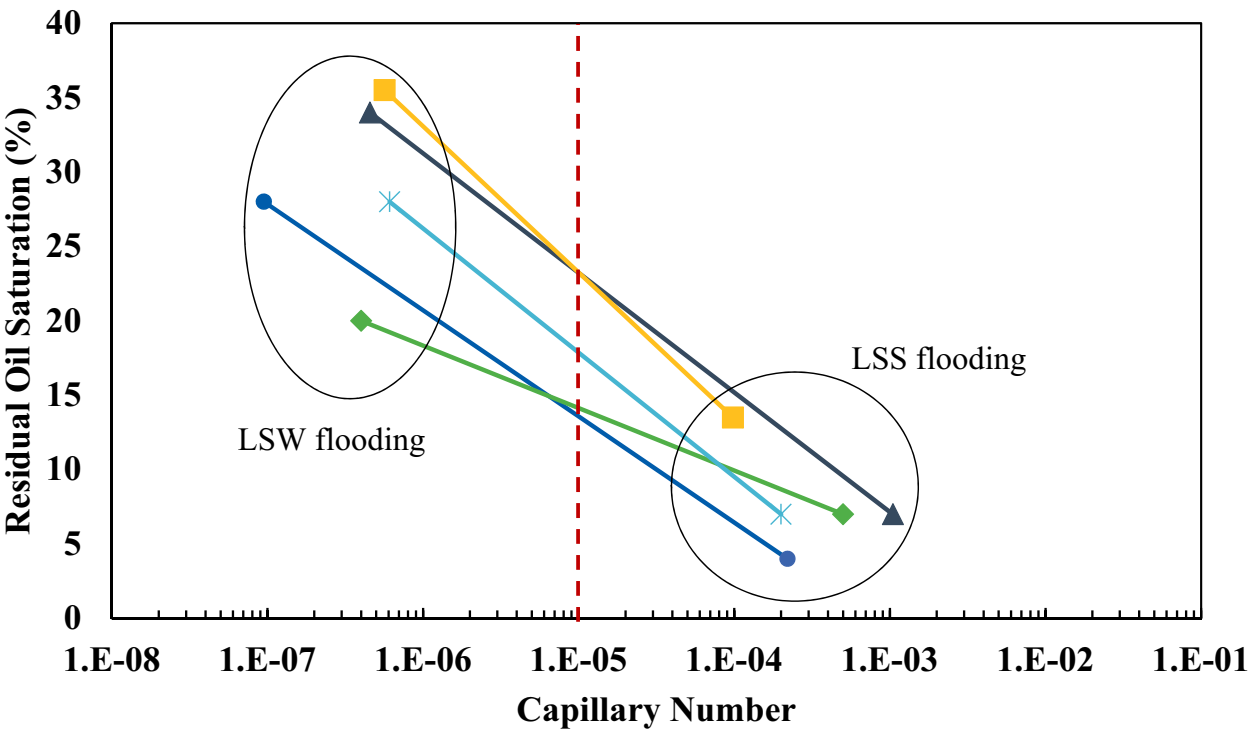

assistance of the surfactant. Different types and volumes of surfactants were used in the LSS experiments by researchers, which leads to different responses of rock-fluid (see Table 1 and Table 2). On the other hand, the PSD varies in different samples, resulting in the different potential of the EOR for each core sample. Therefore, LSS data are more scattered compared to LSW data.

The majority of the SF data are also located in this region. SF data show an average of 5\% higher ROS compared to LSS data. In addition, the reduction in ROS for the SF method is less than the LSS method at the same increment of capillary number. This observation is in line with Spildo et al. (2012), where it was concluded that reduction of IFT in LSS floods generates an increase in oil recovery, which exceeds the expected performance of injecting a surfactant solution with the same reduction in IFT but without the low salinity contribution (Spildo et al. 2012). To deeply investigate the mentioned statement, the nominated data for SF and LSS experiments were compared in terms of IFT reduction and differential of ROS. Table 3 presents the nominated SF and LSS experiments for further investigation. It should be mentioned that the same data are used in this section as were used for Fig. 4, except for Riisøen's experiment, which is excluded as the IFT data were not available.

Figure 5 shows the IFT ratio and differential of ROS for the experiments presented in Table 3.

In this figure, the IFT ratio presents the ratio of the brineoil IFT when the surfactant is absent to when the surfactant is present in the brine. The term "differential ROS" is representative of the differential of ROS values before and
Table 3 Nominated SF and LSS experiments for analysis of their performances

\begin{tabular}{lll}
\hline $\begin{array}{l}\text { Number of sce- } \\
\text { nario }\end{array}$ & Author(s) & Method \\
\hline 1 & Abeysinghe et al. (2012a) & SF \\
2 & Abeysinghe et al. (2012b) & SF \\
3 & Abeysinghe et al. (2012b) & SF \\
4 & Alagic and Skauge (2010) & LSS \\
5 & Alagic et al. (2011) & LSS \\
6 & Spildo et al. (2012) & LSS \\
7 & Johannessen and Spildo (2013) & LSS \\
\hline
\end{tabular}

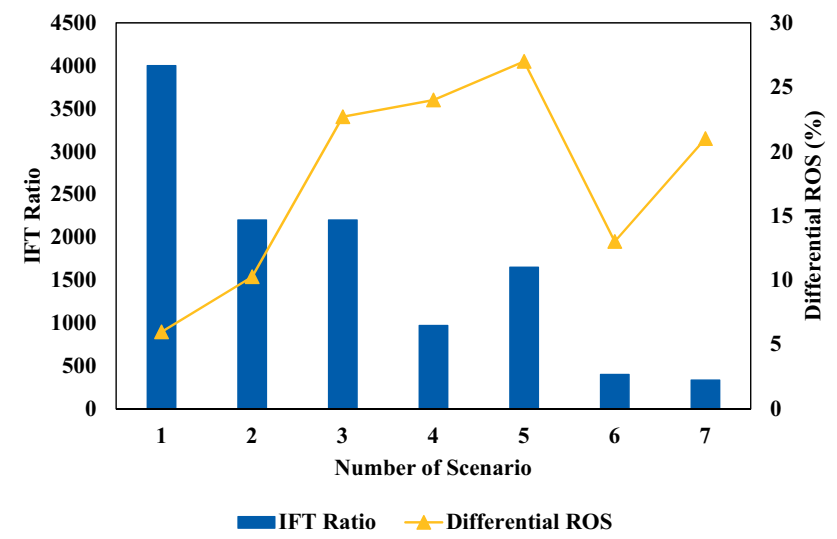

Fig. 5 Performance comparison between LSS and SF methods 
after the SF/LSS processes. The IFT ratio of the SF method (Average of 2800) is higher than the LSS method (Average of 837), which means that the added surfactant could reduce the IFT between brine-oil for SF more than LSS. The values of the differential ROS compared to the magnitude of the IFT ratio for SF are lower than with LSS. It can be inferred that, although the higher IFT ratio of the SF method caused lower capillary trapping, the LSS method could be more effective in terms of ROS reduction. This figure supports the mentioned statement that by using LSS, much less ROS can be achieved compared to using SF.

Another arguable phenomenon is capillary end-effect. This phenomenon causes oil to remain in the core sample due to the discontinuity of the wetting phase (Huang and Honarpour 1998). Adding surfactant to the injection stream (brine and/or LSW) during SF or LSW flooding may reduce the capillary end-effect, which leads to incremental oil production at the same ROS. The effect of capillary end-effect can be minimized/eliminated by applying a series of high injection rates, called bump floods, or choosing the appropriate length of the core samples and injection rate, which have been applied in all experiments. Therefore, the observed incremental oil recovery can be attributed to the abovementioned reasons but not a reduction in capillary end-effect.

As mentioned, 2 reasons (reduction of capillary force and redistribution of the oil and/or destabilized oil layers) might be responsible for the stunning performance of LSS flooding when LSW was already flushed into porous media. The second mentioned reason, redistribution of the oil and/ or destabilized oil layers because of rock/brine/oil interaction as a result of LSW flooding, does not contribute to the SF method. Therefore, in SF, the IFT reduction due to the added surfactant causes the invasion of the brine solution into smaller pores and results in bringing trapped oil into production, but there is no redistributed oil and/or destabilized oil layers to be brought to the production. Figures 6 and 7 schematically illustrate this hypothesis. Figure 6 shows the configuration of the fluids in a pore after SF, for both water-wet and oil-wet mediums. Regarding this figure, a layer of oil is sandwiched between formation brine and surfactant solution. This amount of oil can be the target of the LSW flooding follow by LSS flooding, where the interactions between rock/oil/brine can redistribute the volume of oil left and/or destabilize the oil layers, as shown in Fig. 7.

The third region stands for the capillary numbers $10^{-2}$ and greater. A few data of LSS and SF are observed in this region, which shows that it is difficult to reach capillary numbers of $10^{-2}$ and greater. The LSS data in this region show high ROS values with an average of $13 \%$, which illustrates that the performance of the LSS method is not prominent. Flooding a surfactant could be more effective when the capillary number is within the third region, where the average ROS is $6.7 \%$ for the SF method. Therefore, the SF method is recommended to achieve lower ROS when

Fig. 6 Microscopic analysis of surfactant flooding in left water-wet medium and right oil-wet medium. The deep blue is representative of the formation brine, the brown represents the oil, and the white represents the surfactant solution (Yadali Jamaloei and Kharrat 2009 adapted from Yadali Jamaloei and Kharrat (2009))
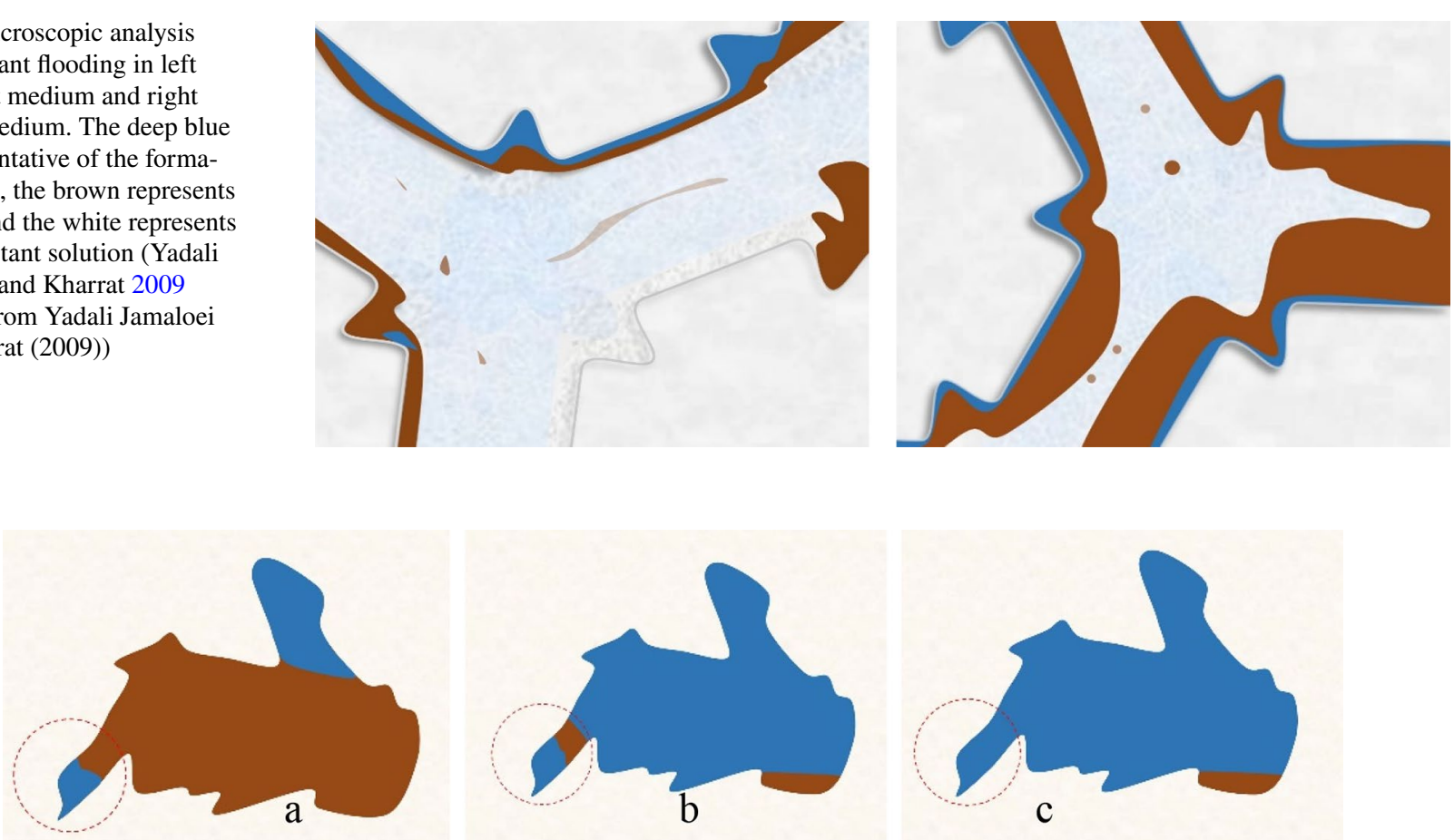

Fig. 7 Displacement of trapped oil: a initial water saturation, $\mathbf{b}$ residual oil saturation after LSW flooding, and $\mathbf{c}$ residual oil saturation after LSS flooding. Red represents the oil, and blue represents the brine phase (Mirchi 2018 adapted from Mirchi (2018))

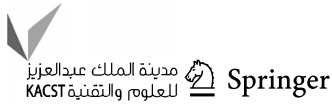


operating within this region. It should be mentioned that the capillary numbers within this range could be reached by using the optimum salinity of water or a high portion of the surfactant. This way, the challenge of high rate of surfactant retention may arise which results in environmental damages and/or economically impractical operations.

\section{Conclusion}

In this study, the performance of the hybrid low salinity surfactant method is compared with low salinity water and surfactant flooding. For this purpose, a dataset consisting of residual oil saturation and capillary number values is established using data presented by scholars. The capillary desaturation curve was used to study the effective mechanisms on residual oil saturation at different capillary numbers for the mentioned EOR techniques. Based on the three identified regions in the capillary desaturation curve, it is concluded that:

- A high density of the low salinity water data is observed in the first identified region, with an average of $32 \%$ of residual oil saturation.

- A stunning performance of low salinity surfactant flooding is observed in the second identified region (capillary numbers in the range of $10^{-5}$ and $10^{-2}$ ) in terms of residual oil saturation compared to the low salinity water method and surfactant flooding as a result of taking advantage of both methods.

- The low salinity surfactant method is able to increase the capillary number by up to three orders of magnitude and decrease the magnitude of ROS up to $30 \%$, which highlights its advantages over the SF method.

- Residual oil saturation of the low salinity surfactant method shows an average of 5\% lower values compared to the surfactant flooding method.

- Although a higher IFT ratio of surfactant flooding caused lower capillary force, flooding of low salinity water could be more effective in terms of the reduction in the magnitude of residual oil saturation.

- The redistribution of the oil and/or destabilization of the oil layers are known as a reason behind the better performance of low salinity water flooding.

- The surfactant flooding is found to be more effective in high capillary numbers (third identified region).

Acknowledgements The authors would like to thank Nazarbayev University for supporting this research through the NU Faculty Development Competitive Research Grants program (Grant number 110119FD4541).

\section{Compliance with ethical standards}

Conflict of interest On behalf of all the co-authors, the corresponding author states that there is no conflict of interest.

Open Access This article is licensed under a Creative Commons Attribution 4.0 International License, which permits use, sharing, adaptation, distribution and reproduction in any medium or format, as long as you give appropriate credit to the original author(s) and the source, provide a link to the Creative Commons licence, and indicate if changes were made. The images or other third party material in this article are included in the article's Creative Commons licence, unless indicated otherwise in a credit line to the material. If material is not included in the article's Creative Commons licence and your intended use is not permitted by statutory regulation or exceeds the permitted use, you will need to obtain permission directly from the copyright holder. To view a copy of this licence, visit http://creativecommons.org/licenses/by/4.0/.

\section{References}

Abeysinghe KP, Fjelde I, and Lohne A (2012). Displacement of Oil by surfactant flooding in mixed-wet condition, In International Symposium of the society of core analysts held in Aberdeen, Scotland, UK, 2012, 27-30

Abeysinghe KP, Fjelde I, and Lohne A (2012) Dependency of remaining oil saturation on wettability and capillary number, presented at the SPE Saudi Arabia section technical symposium and exhibition, Al-Khobar, Saudi Arabia, 2012/1/1/, 2012. Available: https ://doi.org/10.2118/160883-MS

Akai T, Blunt MJ, Bijeljic B (2020) Pore-scale numerical simulation of low salinity water flooding using the lattice Boltzmann method. J Coll Interface Sci 566:444-453

Al-Abri H, Pourafshary P, Mosavat N, Al Hadhrami H (2019) A study of the performance of the LSWA CO2 EOR technique on improvement of oil recovery in sandstones. Petroleum. 5(1):58-66

Alagic E, Skauge A (2010) Combined low salinity brine injection and surfactant flooding in mixed-wet sandstone cores. Energy Fuels 24(6):3551-3559

Alagic E, Spildo K, Skauge A, Solbakken J (2011) Effect of crude oil ageing on low salinity and low salinity surfactant flooding. J Petroleum Sci Eng 78(2):220-227

Austad T, Rezaeidoust A, and Puntervold T (2010) Chemical mechanism of low salinity water flooding in sandstone reservoirs, presented at the SPE improved oil recovery symposium, Tulsa, Oklahoma, USA, 2010/1/1/, 2010. Available: https://doi. org/10.2118/129767-MS

Bartels WB, Mahani H, Berg S, Hassanizadeh SM (2019) Literature review of low salinity waterflooding from a length and time scale perspective. Fuel 236:338-353

Bernard GG (1967) Effect of floodwater salinity on recovery of oil from cores containing clays, presented at the SPE California regional Meeting, Los Angeles, California, 1967/1/1/, 1967. Available: https://doi.org/10.2118/1725-MS

Christensen M and Tanino Y, Residual oil saturation under mixed-wet conditions: optimal wettability revisited, In Proc International symposium of the society of core analysts, SCA2018-011, Trondheim, Norway, 2018

Darvish Sarvestani A, Ayatollahi S, Bahari Moghaddam M (2019) Smart water flooding performance in carbonate reservoirs: an experimental approach for tertiary oil recovery. J Petroleum Explor Prod Technol 9(4):2643-2657 
Druetta P, Picchioni F (2020) Surfactant flooding: The influence of the physical properties on the recovery efficiency. Petroleum. 6(2):149-162

Fathi Z, Ramirez FW (1984) Optimal injection policies for enhanced oil recovery: part 2-surfactant flooding. Soc Petroleum Eng J 24(03):333-341

Fouladi MM, Rostami B, Pourafshari P (2019) Effects of the presence of fines on the performance of low salinity waterflooding. Special Topics Rev Porous Media: an Int J 10(2):155-169

Garnes JM, Mathisen AM, Scheie A, and Skauge A (1990). Capillary number relations for some north, sea reservoir sandstones, presented at the SPE/DOE enhanced oil recovery symposium, Tulsa, Oklahoma, 1990/1/1/, 1990. Available: https://doi. org/10.2118/20264-MS

Gbadamosi AO, Junin R, Manan MA, Agi A, Yusuff AS (2019) An overview of chemical enhanced oil recovery: recent advances and prospects. Int Nano Lett 9(3):171-202

Glover CJ, Puerto MC, Maerker JM, Sandvik EL (1979) Surfactant phase behavior and retention in porous media. Soc Petroleum Eng J 19(03):183-193

Healy RN, Reed RL, Stenmark DG (1976) Multiphase microemulsion systems. Soc Petroleum Eng J. 16(03):147-160

Hirasaki GJ, van Domselaar HR, Nelson RC (1983) Evaluation of the salinity gradient concept in surfactant flooding. Soc Petroleum Eng J 23(03):486-500

Hosseinzade Khanamiri H, Baltzersen Enge I, Nourani M, Stensen JÅ, Torsæter O, Hadia N (2016) EOR by low salinity water and surfactant at low concentration: impact of injection and in situ brine composition. Energy Fuels 30(4):2705-2713

Hosseinzade Khanamiri H, Nourani M, Tichelkamp T, Stensen JÅ, Øye G, Torsæter O (2016b) Low-salinity-surfactant enhanced oil recovery (EOR) with a new surfactant blend: effect of calcium cations. Energy Fuels 30(2):984-991

Huang DD, Honarpour MM (1998) Capillary end effects in coreflood calculations. J Petroleum Sci Eng. 19(1):103-117

Jadhunandan PP, Morrow NR (1995) Effect of wettability on waterflood recovery for crude-oil/brine/rock systems. SPE Reserv Eng. 10(01):40-46

Johannessen AM, Spildo K (2013) Enhanced oil recovery (EOR) by combining surfactant with low salinity injection. Energy Fuels 27(10):5738-5749

Khanamiri HH, Torsæter O, and Stensen JA (2015). Experimental study of low salinity and optimal salinity surfactant injection, presented at the EUROPEC 2015, Madrid, Spain, 2015/6/1/, 2015. Available: https://doi.org/10.2118/174367-MS

Khosravi V, Mahmood SM, Zivar D, Sharifigaliuk H (2020) Investigating the applicability of molecular dynamics simulation for estimating the wettability of sandstone hydrocarbon formations. ACS Omega 5(36):22852-22860

Lager A, Webb KJ, Black CJJ, Singleton M, Sorbie KS (2008) Low salinity oil recovery-an experimental investigation. Petrophys, Conf P 49(1):28-35

Lake LW (1989) Enhanced oil recovery. Old Tappan, NJ; Prentice Hall Inc., United States

Lee SY, Webb KJ, Collins IR, Lager A, Clarke SM, O‘Sullivan M, Routh AF (2011) Low salinity oil recovery-increasing understanding of the underlying mechanisms of double layer expansion. In: IOR 2011-16th European symposium on improved oil recovery. European Association of Geoscientists \& Engineers, pp cp-230

Lin Q, Bijeljic B, Berg S, Pini R, Blunt MJ, Krevor S (2019) Minimal surfaces in porous media: pore-scale imaging of multiphase flow in an altered-wettability bentheimer sandstone. Phys Rev E. 99(6):063105
Mahani H, Keya AL, Berg S, Bartels W-B, Nasralla R, Rossen WR (2015) insights into the mechanism of wettability alteration by low-salinity flooding (LSF) in carbonates. Energy Fuels. 29(3):1352-1367

Mahzari P and Sohrabi M (2015). Impact of micro-dispersion formation on effectiveness of low salinity waterflooding, presented at the IOR 2015-18th European symposium on improved oil recovery, 2015. Available: https://www.earthdoc.org/content/ papers/https://doi.org/10.3997/2214-4609.201412103

Martin JC (1959). The effects of clay on the displacement of heavy oil by water, presented at the Venezuelan Annual meeting, Caracas, Venezuela, 1959/1/1/, 1959. Available: https://doi. org/10.2118/1411-G

Massarweh O, Abushaikha AS (2020) The use of surfactants in enhanced oil recovery: a review of recent advances. Energy Rep 6:3150-3178

McGuire PL, Chatham JR, Paskvan FK, Sommer DM, and Carini FH (2005) Low salinity oil recovery: an exciting new EOR opportunity for Alaska's North slope, presented at the SPE Western regional meeting, Irvine, California, 2005/1/1/, 2005. Available: https://doi.org/10.2118/93903-MS

Mirchi V (2018) Pore-scale investigation of the effect of surfactant on fluid occupancies during low-salinity waterflooding in oil-wet carbonates, presented at the SPE Annual technical conference and exhibition, Dallas, Texas, USA, 2018/9/24/, 2018. Available: https ://doi.org/10.2118/194045-STU

Moradpour N, Karimova M, Pourafshary P, Zivar D (2020) Effects of slug size, soaking, and injection schemes on the performance of controlled ions water flooding in carbonates. ACS Omega. 5(29):18155-18167

Morrow N, Buckley J (2011) Improved oil recovery by low-salinity waterflooding. J Petroleum Technol 63(05):106-112

Nelson RC, Pope GA (1978) Phase relationships in chemical flooding. Soc Petroleum Eng J 18(05):325-338

Nwidee LN, Theophilus S, Barifcani A, Sarmadivaleh M and Iglauer S (2016) EOR processes, opportunities and technological advancements. Chemical Enhanced Oil Recovery (cEOR)-a Practical Overview, 2016, pp 2-52

Oughanem R, Youssef S, Bazin B, Maire E, and Vizika O. Pore-scale to core-scale aspects of capillary desaturation curves using CT-scan imaging. In IOR 2013-17th European symposium on improved oil recovery, 2013, pp cp-342-00022: European Association of Geoscientists and Engineers

Pourafshary P, Moradpour N (2019) Hybrid EOR methods utilizing low-salinity water, enhanced oil recovery processes-new technologies. IntechOpen. https://doi.org/10.5772/intechopen.88056

Riisøen S (2012) Effect of combined low salinity and surfactant injection on oil recovery in aged Bentheimer sandstones at different temperatures Master, The University of Bergen

Sahimi M (1993) Flow phenomena in rocks: from continuum models to fractals, percolation, cellular automata, and simulated annealing. Rev Mod Phys 65(4):1393-1534

Santoso R, Torrealba V, Hoteit H (2020) Investigation of an improved polymer flooding scheme by compositionally-tuned slugs. Processes. 8(2):197

Schilling BER, Stensen J-Å, Øren P-E (1995) Effects of pore-scale displacement mechanisms and small-scale heterogeneities on oil recovery by surfactant flooding. Geological Soc, London, Special Publ 84(1):209-218

Shabani A, Zivar D (2020) Detailed analysis of the brine-rock interactions during low salinity water injection by a coupled geochemical-transport model. Chem Geology 537:119484

Sheng JJ (2015) Status of surfactant EOR technology. Petroleum 1(2):97-105 
Spildo K, Johannessen AM, and Skauge A (2012). Low salinity waterflood at reduced capillarity, presented at the SPE improved oil recovery symposium, Tulsa, Oklahoma, USA, 2012/1/1/. Available: https://doi.org/10.2118/154236-MS

Tang G-Q, Morrow NR (1999) Influence of brine composition and fines migration on crude oil/brine/rock interactions and oil recovery. $\mathrm{J}$ Petroleum Sci Eng 24(2):99-111

Tavassoli S, Kazemi Nia Korrani A, Pope GA, Sepehrnoori K (2016) Low-salinity surfactant flooding - a multimechanistic enhancedoil-recovery method. SPE J 21(03):744-760

Torrealba VA, Hoteit H (2019) Conformance improvement in oil reservoirs by use of microemulsions. SPE Reserv Eval Eng 22(3):952-970

Uren LC, Fahmy EH (1927) Factors influencing the recovery of petroleum from unconsolidated sands by waterflooding,. Transactions of the AIME 77(1):318-335

Vledder P, Gonzalez IE, Carrera Fonseca JC, Wells T, Ligthelm DJ (2010) Low salinity water flooding: proof of wettability alteration on a field wide scale, presented at the spe improved oil recovery symposium, Tulsa, Oklahoma, USA, 2010/1/1/. Available: https ://doi.org/10.2118/129564-MS

Yadali Jamaloei B, Kharrat R (2009) Analysis of microscopic displacement mechanisms of dilute surfactant flooding in oil-wet and water-wet porous media. Trans Porous Media. 81(1):1-19

Zhang G, Yu J, Du C, Lee R (2015). Formulation of surfactants for very low/high salinity surfactant flooding without alkali, presented at the SPE international symposium on oilfield chemistry, The Woodlands, Texas, USA, 2015/4/13/. Available: https://doi. org/10.2118/173738-MS

Publisher's Note Springer Nature remains neutral with regard to jurisdictional claims in published maps and institutional affiliations. 